\title{
Repetition and practice effects in a lexical decision task*
}

\author{
GARY B. FORBACH $\dagger$, ROBERT F. STANNERS, and LARRY HOCHHAUS \\ Oklahoma State University, Stillwater, Oklahoma 74074
}

\begin{abstract}
Ss classified visually presented verbal units into the categories "in your vocabulary" or "not in your vocabulary." The primary concern of the experiment was to determine if making a prior decision on a given item affects the latency of a subsequent lexical decision for the same item. Words of both high and low frequency showed a systematic reduction in the latency of a lexical decision as a consequence of prior decisions (priming) but did not show any reduction due to nonspecific practice effects. Nonwords showed no priming effect but did show shorter latencies due to nonspecific practice. The results also indicated that many (at least 36) words can be in the primed state simultaneously and that the effect persists for at least $10 \mathrm{~min}$. The general interpretation was that priming produces an alteration in the representation of a word in memory and can facilitate the terminal portion of the memory search process which is assumed to be random.
\end{abstract}

Some recent experiments (Meyer \& Schvaneveldt, 1971; Schvaneveldt \& Meyer, 1971; Meyer, Schvaneveldt, \& Ruddy, 1972) have demonstrated semantic priming effects in memory using a word-nonword classification task. The results indicate that Ss can make faster lexical decisions for primed, as compaired to unprimed, words. One such priming technique (Meyer et al, 1972) consists of sequentially presenting a pair of semantically related words, e.g., $B R E A D-B U T T E R$, and requiring a lexical decision for each. A positive decision for BUTTER is faster if preceded by $B R E A D$ than if preceded by an unassociated word such as NURSE. The priming technique in a word-nonword classification task appears to offer a very general and useful method for identifying and measuring characteristics of the functional organization of memory.

Another kind of priming effect was suggested in a tachistoscopic recognition experiment by Morton (1964) in which Ss often mistakenly responded with words which had occurred on some earlier trial. This result suggests the possibility of a temporary alteration in the status of a memory representation which makes the item more accessible. The concern of the present experiment was to investigate priming which might result from making a lexical decision about the same letter string more than once during a series of trials. A priming effect based on repetition would indicate that a memory representation may be altered, at least temporarily, simply by its activation. The repetition technique would also have the advantage of allowing for the comparison of priming effects for words and nonwords as a means of investigating possible differences in memory representations for these types of items. Two further objectives of the present study were to determine if

*The present experiment was partially supported by funds from the Oklahoma State University Research Foundation.

tRequests for reprints should be sent to Gary B. Forbach, who is now at the Department of Psychology, Washburn University, Topeka, Kansas 66621. several items would be in the primed state simultaneously and to investigate nonspecific practice effects, the effect on latency of simply practicing word-nonword decisions.

\section{METHOD}

\section{Subjects}

Twenty-three undergraduates served as Ss. They were given a small bonus toward their final grade in introductory psychology as inducement to participate.

\section{Materials}

All items were of the form consonant-consonant-vowelconsonant-consonant. A set of 24 words relatively high in the Thorndike-Lorge word count (HF) was selected so that they differed only in the medial vowel from a list of 24 low-frequency (LF) words, e.g., DRESS, DROSS. A control nonword was constructed for each word pair by substituting a different vowel, e.g., DRISS. To equalize the number of words and nonwords in the total sample, a filler nonword of the CCVCC form was also constructed for each word pair.

The range of frequency for LF words was $1-27$, with a mean of 8.54. The range of frequency for HF words was 31-AA. The mean frequency of HFs was 71.0, using $A A=100$ and $A=50$.

All the materials were typed in uppercase with an IBM sign typewriter, reproduced onto transparencies by the diazochrome method, and mounted in $35-\mathrm{mm}$ slide holders.

\section{Procedure and Design}

The $\mathrm{S}$ was seated at a small table in front of a Plexiglas screen onto which the materials were back-projected to produce a visual angle of approximately $4 \mathrm{deg}$. The basic programming and recording equipment consisted of a Kodak Carousel projector equipped with a solenoid-operated shutter, controlled by an eight-channel Lafayette timer. A Lafayette digital Clock/Counter was used to measure the latencies to the nearest millisecond.

A trial was begun by $S$ pressing a thumb switch held in his nonpreferred hand. The $S$ had been instructed that before he pressed the switch, he should attend closely to the screen and hold between thumb and forefinger of his preferred hand a lightly sprung toggle-type switch. Following activation of the thumb switch by $1 \mathrm{sec}$, an item was presented on the screen. The $\mathrm{S}$ was instructed to indicate by the direction (left or right) of the 


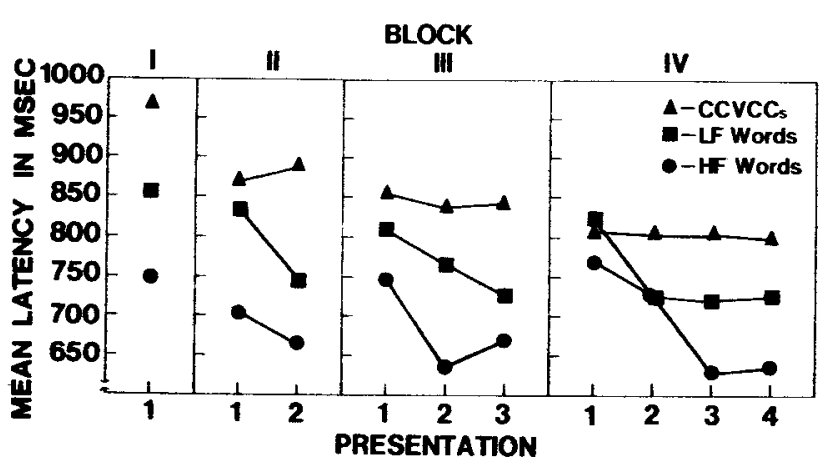

Fig. 1. Mean latency of correct responses as a function of trial blocks, number of presentations, and category.

switch movement whether the item, as a complete unit, was or was not in his vocabulary. The direction of the movement was indicated on a sign next to the switch and was held constant throughout the experiment for a given S. The Clock/Counter started with the presentation of the item and stopped with S's response. Both speed and accuracy were stressed by the instructions, and responding positively to idiosyncratic nicknames was discouraged. The offset of a small lamp below the screen $3 \mathrm{sec}$ after S's response signaled that he could begin a new trial whenever he was ready.

To avoid a confound of the effect of nonspecific practice with the effect of number of presentations, the experimental session was divided into four periods (blocks) after the method of Fishler and Juola (1971). From each category of material, six items were assigned randomly to appear for the first time in each of the four blocks, with the restriction that word frequency be equated between blocks. For HF words, the average frequency was $74.0,63.5,71.8$, and 78.0 , respectively; for LF words, the average frequency was $8.50,8.66,8.50$, and 8.50 .

Block I trials involved presentation of 24 items. In each subsequent block, all previous items and 24 new items were presented. Accordingly, there were $24,48,72$, and 96 trials in Blocks I-IV, respectively, and the experiment consisted of 240 trials, with one, two, three, or four presentations of particular items.

An experimental session lasted approximately $50 \mathrm{~min}$. Before seeing the experimental materials, $\mathrm{S}$ listened to tape-recorded instructions and had 40 practice trials on items similar to the experimental materials. Within each block, order of material was randomized and two Ss were tested on each random order. Direction of switch movement for signification of whether an item was or was not in S's vocabulary was balanced between Ss.

\section{RESULTS}

For each $\mathrm{S}$, the units of analysis were subcondition scores, each computed from the latencies of the six representatives of a category which had been presented the same number of times. Only "correct" (in agreement with the category system) latencies were used in computing a subcondition, score, which was the antilogarithm of the mean log latency for a subcondition. All scores were based on at least three latencies, and $95 \%$ on four or more. Since no more than three errors for a given subcondition were allowed, $10 \mathrm{Ss}$ who made four or more errors in at least one subcondition had to be replaced. About $73 \%$ of the S rejection was due to errors in classification of LF words.

The data in Blocks II, III, and IV allow the assessment of the effects of number of presentations and type of material at three different levels of nonspecific practice. Figure 1 depicts the relationships among the means for HF words, LF words, and CCVCCs in each block. The means for Block I are included as reference points. The analysis for each block was completely within-Ss, and the variables were category, either HF word, LF word, or CCVCC, and number of presentations. For all analyses, only effects with probability values at or below the .05 level were considered significant.

In Block II, the means for categories of items appear to be well separated, and this effect is statistically reliable, $F(2,44)=40.98\left(s_{\bar{x}}=30.94\right)$. The downward trend in mean latency over the first two presentations for LF and HF words but not for CCVCCs is reflected by a significant Category by Presentation interaction effect, $\mathrm{F}(2,44)=8.53\left(\mathrm{~s}_{\overline{\mathrm{x}}}=18.58\right)$.

A very similar pattern of means occurs in Blocks III and IV. In Block III, the effect of catcgory is significant, $\mathrm{F}(2,44)=34.28\left(\mathrm{~s}_{\overline{\mathrm{x}}}=33.55\right)$, as is the Category by Presentation interaction effect, $F(4,88)=5.05\left(\mathrm{~s}_{\overline{\mathrm{x}}}=\right.$ 19.52). In Block IV, the same effects appear: for category, $F(2,44)=19.12\left(s_{\overline{\mathrm{x}}}=36.96\right)$, and for Category by Presentation, $F(6,132)=6.39\left(s_{\bar{x}}=21.06\right)$.

The blocking procedure also allowed for the assessment of a nonspecific practice effect on latency. Figure 2 presents the mean latencies for the first presentation of an item within each block, which represents the effect of nonspecific practice only. The analysis included the variables nonspecific practice (NP), with four levels, and category. As in the previous analyses, category produced a sizable effect, $F(2,44)=$ $24.74\left(s_{\overline{\mathrm{x}}}=38.37\right)$. Figure 2 indicates a downward trend in the mean latency for CCVCCs but not for words of either frequency, and this pattern is reflected by the significant $\mathrm{NP}$ by Category interaction effect, $\mathrm{F}(6,132)=$ $6.55\left(s_{\bar{x}}=22.53\right)$.

Error rates for the three major categories of materials were also examined. In the order HF words, LF words, and CCVCCs, the error rates were $1.6 \%, 7.6 \%$, and $3.3 \%$. Although there were too few error latencies in each subcondition for a statistical analysis, the mean latencies of correct and incorrect trials for the first presentation of items were calculated by averaging across the four blocks. In the order HF words, LF words, and CCVCCs, the error latencies were 811,842 , and 839 . For correct response latencies, the corresponding means were 741 , 830 , and 874.

\section{DISCUSSION}

The effect of number of presentations for words indicates that activating a memory representation of a word leads to faster activation of the same memory representation on subsequent occasions. The lack of a presentation effect for CCVCCs suggests that $\mathrm{S}$ does not learn the nonwords in this type of task in the sense of storing a representation in memory. Since there is no 
long-term memory representation for CCVCCs, no priming effect occurs. Quite a few words (at least 36) may be in the primed state simultaneously, and the effect persists for a substantial period of time. The second appearance of a given item in Block II would occur after an average of 36 trials (approximately $4-6 \mathrm{~min}$ ). The corresponding average in Block III is 60 trials (6-10 min) and in Block IV is 84 trials $(8-14 \mathrm{~min})$. Quite clearly, the effect operates in long-term rather than short-term memory.

The effect of number of presentations on words of high and low Thorndike-Lorge frequency has an implication for the question of whether lexical search is an ordered process as suggested by Stanners and Forbach (1973) or is at some stage a random process as proposed by Rubenstein, Garfield, and Millikan (1970). The overall strong relationship between frequency and lexical search latency (Rubenstein et al, 1970; Stanners \& Forbach, 1973) was interpreted by Stanners and Forbach (1973) as reflecting a serial search of a memory subset in which the ordinal position of a memory representation in the subset was based on frequency of experience. According to this view, a priming effect could be the result of changing the ordinal position in which a given memory representation is checked; a recently primed item would have been moved up in the order of search, at least temporarily. The extent of change in position produced by priming would be expected to be greater for low-frequency items as compared to high-frequency items, which would already be near the starting point of the subset. However, the present results show that the priming effect is essentially the same for low-frequency and high-frequency items.

The required alteration in the model should accommodate both the similarity of priming effects for high- and low-frequency words and the differences in latency attributable to frequency. One possibility is a hierarchical type of search process on the order of that proposed by Rubenstein et al (1970). As in the earlier conception of Stanners and Forbach (1973), a subset of memory would be designated on the basis of consonant information from the item. Within this subset, smaller subsets would each be randomly searched and the order of entering the smaller subsets would be determined by language frequency. The priming effect would be based on some modification of the memory representation, possibly a time tag of some sort, which would facilitate the terminal random phase of the search.

The finding that nonspecific practice affects words and nonwords differentially is of methodological interest. The nonspecific practice effect was present even after 180 trials, indicating the need for care in the design of experiments to avoid the confounding of nonspecific practice with other variables.

The decrease in latency as a result of nonspecific practice for CCVCCs coupled with the absence of such a decrease for words of either frequency level suggests a basis for the effect. If the nonspecific effect were attributable to changes in the speed of encoding an item

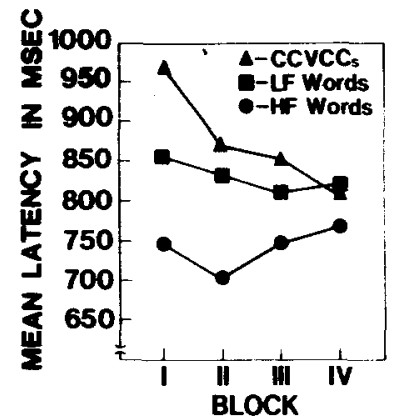

Fig. 2. Mean latency of correct responses as a function of trial blocks and category for only the first presentation of items.

or to that portion of the search resulting in activation of the memory representation, then the effect should have been observed for words. The present results suggest that the effect is due to some process which follows the initial search; possibly Ss tend to do less "rechecking" of search subsets as they acquire more experience in rejecting CCVCCs. This effect would not be expected for words, since no rechecking would be necessary after finding an appropriate entry.

The pattern of means of the error data is in agreement with the results of two previous experiments (Stanners, Forbach, \& Headley, 1971; Stanners \& Forbach, 1973). One recurrent relationship is that errors on words tend to have longer latencies than do correct responses; presumably $\mathbf{S}$ makes an unsuccessful exhaustive search on an error trial. The other relationship is that errors on CCVCCs have somewhat shorter latencies than do correct responses. The interpretation is that $\mathrm{S}$ mistakenly finds a match before exhausting the subset.

\section{REFERENCES}

Fishler, I., \& Juola, J. F. Effects of repeated tests on recognition time for information in long-term memory. Journal of Experimental Psychology, 1971, 91, 54-58.

Meyer, D. E., \& Schvaneveldt, R. W. Facilitation in recognizing pairs of words: Evidence of a dependence between retrieval operations. Journal of Experimental Psychology, 1971, 90, 227-234.

Meyer, D. E., Schvaneveldt, R. W., \& Ruddy, M. G. Activation of lexical memory. Paper presented at the meeting of the Psychonomic Society, St. Louis, Missouri, November 1972.

Morton, J. The effects of context on the visual duration threshold for words. British Journal of Psychology, 1964, 55, 165-180.

Rubenstein, H. R., Garfield, L., \& Millikan, J. A. Homographic entries in the internal lexicon. Journal of Verbal Learning \& Verbal Behavior, 1970, 9, 487-494.

Schvaneveldt, R. W., \& Meyer, D. E. Retrieval and comparison processes in semantic memory. Paper presented at the Fourth International Symposium on Attention and Performance, Boulder, Colorado, August 16-21, 1971.

Stanners, R. F., \& Forbach, G. B. Analysis of letter strings in word recognition. Journal of Experimental Psychology, 1973, 98, 31-35.

Stanners, R. F., Forbach, G. B., \& Headley, D. B. Decision and search processes in word-nonword classification. Journal of Experimental Psychology, 1971, 90, 45-50.

(Received for publication August 20, 1973; revision received October $10,1973$. ) 